\title{
A GENEALOGY OF ETHNOGRAPHY HELPS UNDERSTANDING ITS EVERLASTING RELEVANCE
}

\author{
Oscar Alfredo Forero Larrañaga ${ }^{1}$
}

\section{Introduction}

In the current era of Anthropocene, both developing and developed countries have embarked in a mission to develop territorial innovation systems for increasing sustainability of livelihoods and to encourage socio-ecological resilience. The last two decades of the 20th century saw the increase of applied research and development with focus in achieving sustainability targets. Most countries in the developing world made use of the millennium development goals (MDG) framework to advance political agendas of poverty reduction and socio-economic equality.

Although biodiversity conservation, sustainability and adaptation to climate change were targeted by the MDG framework, some organisations and theorist of international development advised to strengthen methodologies and developing indicators and evaluation assessments to allow governments to move faster in that direction. Academics, social movements and industry agreed this was necessary, considering the increasing resilience challenge to socio-ecosystems. All evidence suggest adaptation would be ever more difficult because we have intensely accelerated the rate of biodiversity loss (CBD 2010); increased rates of soil degradation and continued observing advance of desertification (UNCCD 2014); and the rate of rise in global temperatures (and of sea level) is faster than estimated (Scherer 2012).

Scientists, social movements and industry representatives, all urged governments to better incorporate resilience of socio-ecosystems to the new development goals framework. The Sustainable Development Goals - Agenda 2030 (SDG) were issued attending to this plea. This is not a trivial change; neither is one that was possible during the 20th century. This change in international development policy was possible only because of the developments of sustainability science, and the procurement of evidence that the impact of human activities in the biosphere and atmosphere are of such scale that it allowed almost complete scientific consensus that we have entered a new geological era: Anthropocene.

It is worth remembering that the concept of sustainability evolved out of an ethical framework and not from a reductionist scientific one (Forero 2015). The concept of Sustainable Development (SD) itself: "Sustainable development is development that meets the needs of the present without compromising the ability of future generations to meet their own needs" (UNO 1987) whilst useful as a moral compass, principle or goal, posed a problem to scientists who were commissioned to developing indicators, assessment methods and precise

${ }^{1}$ Senior Researcher, Dirección Centro De Investigación Obonuco, Corpoica,

Colombia; School of Oriental and African Studies, London Email: oscaralfredo@yahoo.com 
methodologies to monitor advance (or stagnation) towards SD. This is how the science of sustainability came to be.

From the outset, the construction of methodologies of systems of indicator, and of theory in sustainability science, have been the endeavour and product of interdisciplinary or transdisciplinary teams. Political ecologies and science and technology studies (STS) both had called the attention that in the 21 st century, development policy could not be left to an "expert group" alone. For most of the 20th century, development policies were drafted by economists. Only with the surge of sustainability science, were natural scientists, environmentalists and indigenous peoples allowed to contribute meaningfully to the devising and implementing of such policy. Political ecologies across the globe revealed a wealth of knowledge that was being ignored until then. The human rights approach to sustainable development owns a great deal to political ecology. For their part, STS, including anthropology of science, revealed how capital and groups with political and economic interests were influencing, and often blocking intervention from the public, in defining research and innovation paths. Besides their calls for increasing transparency and accountability in the use of tax payers' money for the development of research and innovation, STS also questioned procedures that were preventing public debate and agreement with respect to policy development for innovation.

Transdisciplinary labour is inherent in sustainability science, which has allowed investigating social systems and ecosystems integrally. In the 20th century it was still common to refer to ecosystems and habitats as part of the field (the natural resources base) upon which social systems thrive or collapsed, as if culture and territorialisation, and human relationships in general, were not affected and sometimes shaped by the state ecosystems and habitats. Indigenous people objected to differentiating natural and social systems. They also objected to the definitions of territory that recognised agency to human beings alone (Forero 2015). In similar fashion, environmentalists and ecosystem experts used to conceive of ecosystems and habitats as if their states of relative equilibrium were reached independently of social systems. Today, scientists, independently of their disciplinary background, recognise that the analytic divisions of nature- society and social systems-ecosystems were useful to advance knowledge, but have become insufficient as research bases to address the challenges of Anthropocene.

In simple language, we all have become aware of transformation of what 18th century scholars referred to as the wilderness. There is no "pristine" corner in our planet. All ecosystems and habitats, the entire biosphere, has been affected by human activities, by of our social systems. On the other hand, reproduction of cultural diversity, which is whether human groups with distinctive identities would persists or perish, depends upon their capacity to adapt to the greatest change we have faced, that of global climate change (GCC). Some societies are having to completely transform their livelihoods as the ecosystems and habitats they used to rely upon collapse and become something else, often drastically reducing the quantity and quality of environmental services they can sustainably provide.

Adopting the resilience framework not only as conceptual but as a mobilisation framework, implies developing research methodologies which involve gathering, generating and analysing quantitative and qualitative data. Just as we developed indicators to assess advances in the three basic dimensions of sustainability (environmental, socio-political and economic), 
a similar task is ahead of us with respect to resilience (mitigation and adaptations) of socio-ecosystems to GCC.

With respect to gathering, generating and analysing qualitative data, no methodological development has surpassed ethnography. The ethnographic method encompasses, as we will examine in detail, reflexivity, the constant interrogation of the foundation of our knowledge and epistemology. Ethnographers have helped refine this effective method for understanding and explaining cultural diversity, and for deciphering and describing the diverse epistemologies that have allowed humanity to develop appropriate technologies for adaptation to environmental, economic and political changes.

Importantly, as we will examine, ethnographers had to confront the fact that such a method appeared in the context of imperial expansion and that could and has been used to justify colonialism and imperialism. Recognising and addressing this problem have been challenging, but the methods endures and today sustainability sciences and the development of resilience framework cannot do without ethnography.

\section{Genealogy}

Ethnography can be thought of as a research product; in fact, it is the favourite mode in which anthropologist and ethnologists (ethnographers) present the findings of their research labour. That is ethnography as a genre (Clifford and Marcus 1986, van-Maanen 1988). However, ethnography is overall a qualitative method of social research. Pineda Camacho (1987) referred to the uniqueness of ethnography as a method since its establishment has allowed revealing social facts that remained hidden and unexplored. From its outset ethnography became the qualitative research method par excellence.

Nowadays ethnography is widely used across humanities and social sciences, but also in transdisciplinary research, particularly in applied research projects that look to generate impact. Participatory Action Research (PAR) requires qualitative data analysis; this is the use of ethnographic method (Fals Borda 1984). It also requires acknowledging knowledge co-production between academics and interest groups. Ethnography has also been used in the field of marketing and management (see Nanarpuzha and Sharma 2013; Venkatesh, Crockett, et.al. 2017).

In the 21 st century, with the rise of information communication technologies (ICT) as a tool to advance PAR in development studies, it became important to incorporate ICT to qualitative data analysis (see for instance Tacchi, Slater et.al. 2003). Artists have often used ethnography (see Kruger 2008), sometimes as the bases for performance, and often looking to provoke the public that are presented with undisclosed or uninvited reflections of self and others.

Perhaps through an examination of the genealogy and evolution of ethnography, it would become clear the reasons behind ethnography's wider appeal. It may seem odd to social science students of today, to find that methods for qualitative data analyses did not develop intuitively nor did they precede methods for analysis of quantitative data. To understand why this is so, we need to go back to the 19th century, when positivism was in fashion and those studying "society" were looking to position the discipline in a similar status than that already 
accomplished by the hard sciences. In "The Course in Positive Philosophy", a series of texts published between 1830 and 1842, Auguste Comte first described the epistemology of positivism and its aim. Comte sought to replace the explanations of social change provided by metaphysics and superstition, with objective rational explanations. With positivism, Comte made the empirical goals of the "sociological method" explicit.

Those dedicated to study society in the 19th century had an interest in equating social and physical facts. They aimed to demonstrate that it was possible to conduct social research with the same solidity and reliability as that carried out in the natural sciences. In this context, it is no surprise that statistics and surveys were widely used amongst the new breed of researchers interested in all things social.

There is indeed great scope for the use of statistics and surveys to discover behavioural trends, to predict direction or trajectories chosen by people, and even to establish certain chains of causality. An early example of the use of statistical analysis in sociology is "suicide" (1897) by Emile Durkheim. At first glance, nothing seems more intimate and personal than the causes of suicide, it being a purely individualistic act. However, using statistical and inductive analyses, Durkheim demonstrated that, as he hypothesised, "At any given moment the moral constitution of society establishes the contingent of voluntary deaths" (Durkheim (1897)1951 p.299). Durkheim's proposal was not that correlations are indicative of causality. On the contrary, from the outset Durkheim webbed statistics to theory, his reasoning was that suicide occurs in all societies, and that societies, even when geographically and culturally distant, show similar rates of suicide in the long term. Therefore, societies must have normal rates of suicide. Durkheim hypothesised, and went on to prove, that a higher or abnormal suicide rate indicates stress or failure of social structures (Coser 1977).

By the end of the 19th century it seemed possible to social scientists that social facts could be treated as things or events, just like the experiments carried out in natural sciences. They proposed that although social facts were not physical entities, methodologically they could be subjected to a similar empirical treatment.

However, when these scholars were working out the surveys and type of measurement required to prove certain hypotheses, they realised that social facts were neither things nor events in the manner conceived by natural scientists. To begin with, social facts were more difficult to define, often requiring the detailed description of context, and the analysis of externally related factors. Oddly enough, social scientists also realised that often causal explanations did not explain occurrence or the manner in which they occurred. By trying to grasp what social facts were, social scientists were forced to rethink about what they meant and for whom? They found themselves in need to investigate the evolution of "meanings".

\section{Towards ethnography}

This new breed of scientists realised that sociology needed dedicating time to the study of diverse types of societies to make 'meaningful' comparisons. They needed to decipher meaning from inside cultural traditions, not just describe it as they saw it, as observations were influenced by the researcher's cultural upbringing. Only with in-depth studies of many different societies could they say something relevant across cultures. Some of these societies inhabited remote regions of the world, some had already vanished and some were still "primitive". 
The route to ethnography required several realizations. A fundamental one was proposed by a student of Durkheim, Simiand (1912), who highlighted that statistics is only a tool of economics, methodologically, a science of the social "encompassed more than number crunching". He alerted scholars of the time to need refining observation. Simiand argued that no conclusions should be drawn from statistical analysis alone or by making assumptions out of context. Bordieu (1984) referred to the program of historical and statistical research that Simiand directed, to argue that social scientists must be aware, as Simiand was, that statistical analysis is not a neutral tool.

Indeed, the formulation of questionnaires, and of the analytical tools to make sense of them, very often reflected a particular epistemology but failed to reveal the meaning the respondents intended to convey by answering one way or another. For surveying and statistical analysis to reveal new routes, new causality chains, unknown social facts and/or new meanings, it demands for survey analyses to be subjected to further treatment, which usually involves conducting in-depth interviews and "reflexivity". It requires for surveys to be conceived only as a facilitating tool for advancing theory.

Another realization happened whilst conducting historical studies of non-European societies. Such studies were largely done having no survey or statistical data. Existing records were in languages and art forms the meaning of which was not always captured by Europeans. They realised that to make sense of observable phenomena, they must learn local languages and traditions. Research of non-Europeans often began by scoping descriptions written by merchants, priests or civil servants, whose narratives were heavily influenced by their own cultural beliefs and the ideologies in fashion.

The descriptions of the 'natives' made by Europeans reflected their own understandings and interpretation of social facts rather than the local understandings and perspectives. Some social scientists became aware of what was later known as Eurocentrism and Ethnocentrism, the interpretation of cultures or social behaviours in terms of the researcher's culture exclusively. Ultimately, social scientists started to realise that the available descriptions were providing justification to imperial expansion. The descriptions they found were biased interpretations of the behaviour of non-Europeans, often full of assumptions. Such accounts often concluded by categorising societies in relation to Europe, placing Europeans as the more civilised or developed in comparison.

Reflexivity was emerging as distinctive to ethnographic work. It made some social scientists to question their role and even made them conscious of historical narratives aimed at "naturalising" the ideologies of Empire. A century later Clifford-Geertz would explain:

\footnotetext{
"The end of colonialism altered radically the nature of the social relationship between those who ask and look and those who are asked and looked at. The decline of faith in brute fact, set procedures, and unsituated knowledge in the human sciences, and indeed in scholarship generally, altered no less radically the askers' and lookers' conception of what it was that were trying to do. Imperialism in its classical form, metropoles and possessions, and Scientism in its, impulsion and billiard balls, fell at more less the same time." (Clifford Geertz 1988: 131-132)
} 
Conquergood (1991) referenced Clifford-Geertz precisely to signal how this realisation made ethnography vulnerable to post-structuralist critique. However, at the time, it provoked ethnographers to work hard refining the method. The ethnographic work continued to make explicit unrevealed political interests that underpinned performance and all modes of representation.

\section{Field Work and Participant Observation}

No genealogy of ethnography would be completed without discussing the work of Malinowski. Malinowski is considered by most anthropologists as the father of modern ethnography. He was conscious of the challenges imposed from the realizations described above and devised a methodology to deal with them. This methodology implied immersing oneself in the life of 'the other' by taking part in daily activities by incorporating the reflection of living experiences into the field diary. The composed narrative, often written in first person, must attempt interpretations of the social from the perspective of the native, but must also reflect upon the researcher's changing understandings and realisations.

To understand things in terms of the other, to get the native meaning, Malinowski argued that it is not enough to ask, it is not enough to observe, one must do with the other, one must have lived the experience; one should try, struggle and do. A novel, and previously ignored, perspective and understanding came from doing and positioning oneself in the position of the other.

Malinowski may or may not have been the first to consciously differentiate between things as seen and understood by an outsider, and things as understood by insiders. But he was the first to systematically use such differences in data analysis. He proposed that the ethnographic method comprehended a period of time, field work, sufficient to conduct participant observation in the activities that local people ("natives") realised cyclically. These could relate to the cycle of cultivars, of rituals, of festivals, pilgrimages, etc. It later became common practice for social anthropologists to remain at least one year among their host communities, in order to participate in activities taking place during all seasons.

To conduct fieldwork, Malinowski proposed learning the local language, conducting participant observation, to collect all available statistical data relevant to addressing theoretical questions, and recording "imponderables" of everyday life. This last one refers to all those activities and behaviours that seem obvious or "natural" to the locals, so much so that they fail to record them when developing narratives or taking part in interviews. Non-experts have sometimes referred to these as "common sense" but of course any ethnographer who have conducted fieldwork is (or should be) aware that that which is common sense to one person may as well be absolute nonsense to her/his neighbour!.

As it was later found out, Malinowski was not as rigorous in recording everything related to these imponderabilia as he advised the ethnographer should be. However he was instinctively right in considering that just asking about it was not enough, that it was also necessary to take part. The necessity of participants' observation was justified, as only by doing, the ethnographer could understand the state of mind of local people. The reaction of everyone, their expressions and bodily reactions must all be recorded. Malinowski argued that the ethnographer needs all of these records for the analysis, as the meaning of social facts, 
including these imponderables would start to be revealed when considering overall patters of thought.

Malinowski was stranded for four years in the Trobriand Islands. He was a Polish citizen living in territory under the control of the British during World War II. He was a prolific ethnographer; in the space of these four years he wrote: Kula: The Circulating Exchange of Valuables in the Archipelagoes of Eastern New Guinea (1920); The Argonauts of the North Pacific (1922); Ethnology and the Study of Society (1922); The Problem of Meaning in Primitive Languages. In the Meaning of Meaning: A Study of Influence of Language Upon Thought and of the Science of Symbolism (1923).

Owen (2011) argued that the success of Malinowski in conducting ethnography, and in positioning fieldwork at the centre of ethnography, were due to three factors ("secrets"): that he had scientific aims (theories, hypotheses), that he lived with the people he was studying and not with other Europeans; and, that he had a systematic method for observation (participant observation and field diary). Let us examine in more detail these three "secrets". To have scientific aims: a main purpose of ethnographic work is to advance theory. Malinowski wanted to explain to the larger scientific public how other societies organised themselves, how they construct meaning and which epistemological routes they followed. To get there, the methodological tool available to a social scientist is ethnography, which allows having a lived experience. Of course, to conduct ethnography requires preparation, and essential to it is to have a theoretical framework: either some hypothesis to prove, some historical facts to investigate, some processes to document, or all of them. This preparation implies, as Owen (2011) reminded, not to have preconceived notions. On the contrary, it is through ethnography itself that the categories of local people, their own perspectives, notions and overall meaning will be revealed.

The second "secret" of success for Owen is to live with the people you are studying, not with others like yourself. Of course, living and doing with and like the other, following their daily patterns is integral to participant observation, without which you cannot have the lived experience. For a novice ethnographer, as it is for someone learning another language, the day when one begins to dream in a local language is memorable. The day when one realises one is thinking in terms of the culture of the other. If you just conduct interviews, even if you speak the language of your interlocutor, you would only have a narrative of the experience, which always is a poor replacement of having the experience itself. Also, if you retrieve to the company of your colleagues after a day of work, you will risk starting interpreting all which was experienced exclusively from the perspective of your own culture.

It is not uncommon for ethnographers to give an account of the perils of being accepted into a host community. Or, of the perils of finding oneself non-belonging to the host community but neither identifying with the culture where one comes from. However, instead of referring to these experiences as anecdotes or challenges, it is part of the ethnographic work to unveil the logic under which such feelings and impressions emerge and came to be. This labour is certainly part of what we call reflective practise. Reflection is intrinsic to ethnographic work.

The third factor (secret) of the ethnographic success is the realization of systematic observations. Systemic observation and its register would depend upon the preparation for 
ethnographic work; this is: Which hypothesis would we like to corroborate? What is the scale of the investigation? Which specific objectives do you want to achieve? All of them relate to having and sticking to a plan to advance theory. The other condition, one that is repeated in ethnographic manuals, is the adequate keeping and management of the fieldwork diary. There is no prototype of diary that will guarantee success, but instead, all of us, who had gone through ethnographic experience, have received and passed on a must advise: be disciplined. With no records, the possibilities of reflective practice or of serious qualitative data analyses are slim.

\section{The fall of an icon and the issue of objectivity}

There was much criticism of Malinowski and questioning of ethnography when his diary, "A Diary in the Strict Sense of the Term", was posthumously published in 1967. Clifford-Geertz (1967) described the anguish of anthropologists and ethnologies, who found out

"that its archetypal fieldworker, rather than being a man of catholic sympathies and deep generosity, a man who his Oceanist contemporary R. R. Marett thought could find his way into the heart of the shiest savage, was instead a crabbed, self-preoccupied, hypochrondriacal narcissist, whose fellow-feeling for the people he lived with was limited in the extreme...: "At bottom I am living outside of Kiriwina although strongly hating the niggers."

By the time the diary was released ethnography had developed and proved its worth as the qualitative analyses methodology par excellence. With all his faults, Malinowski had proved to be highly productive and, whether genuinely or deceitfully, he had "a way with the natives"..."For the truth is that Malinowski was a great ethnographer, and, when one considers his place in time, one of the most accomplished that has yet appeared. That he was also apparently a disagreeable man thus poses something of a problem" (Clifford Geertz 1967)

Malinowski's work was deeply criticised after finding out that perhaps he did not conduct himself as he preached ethnographers should: "the diary consists, for the most part, neither of a description of his daily activities nor a record of the personal impact those activities had upon him." (Clifford Geertz 1967). However, there is one critique that deserved attention, as it refers to the method, not to the man. With all his insistence in having the living experience by doing with the other, Malinowski continued to believe that with analytical inductive capacities, even while conducting participant observation, the ethnographer could remain an objective observer. Malinowski did not contradict positivism in this critical issue: information derived from sensory experience and interpreted through reason and logic would be the only source of all certain knowledge. Malinowski thought that through his ethnographic labour he was gathering empirical evidence to demonstrate what social facts meant.

In other words, a decisive separation of the ethnographic method from positivism was yet to occur. As with many issues related to qualitative data analyses, it was to come as a realisation from conducting ethnographic practice itself. Perhaps an important contribution in that direction was that of Kenneth Pike. Pike was a linguist expert who worked across the Americas. He devised a method to study languages where no dictionary, no alphabet or no grammar were available. In 1954 he proposed that the tools developed for studying languages 
could also be useful to the study of human societies.

Social scientists remained locked within the positivism paradigm and had contradicted each other questioning the issue of "objectivity"; could it be reached through ethnography? Was that really the challenge? Pike proposed a methodological solution. Pike argued that pure objective description was an impossibility, but that a useful differentiation could be established between emic and etic descriptions. Emic and etic are derived from phonemic and phonetic respectively. Emic descriptions would be those made from the perspective of the local/insider, and etic descriptions would be those made from the perspective of the observant/outsider.

Cultural anthropologists, such as Marvin Harris further developed the methodology. Harris argued that an outsider observer can, given skills and practice, propose emic accounts (1976). Also a local, given an adequate context, could make a narration looking as its own culture from a distance, producing an etic account. Harris argued with Pike that objectivity was not possible; but also argued that the purpose of qualitative data analyses was not to claim it. On the contrary, a composed narrative that reflected upon all the accomplished descriptions would be a more desired output from ethnography. Harris proposed a template to be used when analysing field diaries and narratives. In one side, there would be the categories etic and emic, in the other cultural insiders and outsiders such as in the following graph (1):

\begin{tabular}{|l|l|l|}
\hline & Emic & Etic \\
\hline Insider perspective & & \\
\hline Outsider perspective & & \\
\hline
\end{tabular}

Graph 1 (Elaborated by the author to illustrate)

Some ethnographers continued to use "etic" to refer to supposedly objective /outsider accounts, and "emic" to refer to subjective /insider accounts. These ethnographers failed to understand something highlighted by Pike and Harris. Investigating the phonemic of a language forces the researcher to listen and characterise phonemes, sound units of speech specific to a language. The units analysed in phonetics, tone units, are not language specific. Using the methodology to the study of human behaviour it is logical that the natives are better situated to interpret facts and make sense of them from within their own culture. It is also logical that researchers are better equipped to identify cross cultural understandings of social facts. However, nothing prevents locals from producing etic descriptions, or ethnographers from providing a local perspective of the observable phenomena. All narratives count and should be reflected in an ethnography.

A clarification is due; although Pike and Harris both argued in favour of using this differentiation for data analysis, they did not use the concept in the same way; neither had they relied on each other's definitions of the terms. The two men did not meet until 1986 when the use of emic / etic distinction was already widely used. For a recount of the significance of the event and what followed see Headland, Pike, and Harris (1990): "Emics and Etcis: The outsider insider debate". 


\section{Reflexivity and the issue of power inequality}

In the 1980s the use of emic / etic differentiation was so common that its origins were only mentioned in textbooks for undergraduates studying the social sciences. The debates that followed took it as closed to the previous ambivalence with respect to the possibility of reaching objectivity from ethnography. It was settled: not only it wasn't possible, it was also undesirable. Such a path would not allow ethnography to accomplish what it sough most, the capacity and ability to understand and interpret the cultures of others in terms that made sense to them and to fellow scholars as well. The labour of qualitative data analyses was instead dealing with inter-subjectivities (between cultural traditions), and intra-subjectivities (within a culture/tradition). To facilitate such analyses, cultural anthropologists devised filling the matrix of Graph 1 (above).

In any case, independent to our writing style and the chosen form of presenting findings (i.e. case studies, life stories, testimonials, biographies), the ethnographer must do reflective practice. The constructed output, be it an oral or written narrative, a radio program or a cinema, is the product of reflexivity, which brought some new and interesting questions: to which degree are such narratives reflective of the local perspective and understanding? How would the reader know what is narrative and what is an interpretation? What are cross-cultural comparable social facts?

The labour of the ethnographer is not only to create sense, but also to persuade or bring its readers to the conclusion that through ethnography she/he had been able to decipher meaning. And, to make sense of the social, it is essential to research into one's own process of social and intellectual learning. To do both these things systematically is what we call reflective practice.

As the reader could now understand, following this genealogy, the legitimacy or authority of the ethnography is not judged by a possible claim of objectivity. Following post-structuralist critique and a period of self-deprecation that brought about the 'bad history' of ethnographic labour, as instrumental to colonisation, it was no longer possible to defend the idea that somehow, unlike anyone else, ethnographers could cleanse their narratives of any subjectivity (and ideology). Neither was it possible to argue that the encounters between observer and observed were symmetrical. That which makes ethnographies a success or failure is the demonstration that at all times, reflective practices allowed to identify and maintain awareness of the difference between emic and etic narratives and whether they were constructed from within a specific cultural tradition, or from a distance. It is the quality of reflexivity that which is used to legitimise, validate or criticise the ethnographic labour.

Pineda Camacho (1987) highlighted precisely that through ethnographic research we reflectively construct a new image of a society. Therefore, ethnographies are often reflective of a compromise between those images projected by a society from within, and the vision the ethnographer develops, which is invariably influenced by his/her own upbringing; reflective of cultural idiosyncrasies and permeated to the ideologies of her/his time. 
Wanda Pillow (2010, p.175) has discussed the "role of reflexivity as a methodological tool as it intersects with debates and questions surrounding representation and legitimization in qualitative research, within modernist and postmodernist ideologies". Pillow argued there are four common trends in reflective practices: reflexivity as recognition of self, reflexivity as recognition of other, reflexivity as truth, and reflexivity as transcendence. Pillow uses examples to illustrate how different authors seem to pursue more or less a tendency. Pillow (2010) also argued that ethnographers should move out of comfort zones and really engage, which entails "uncomfortable reflexive practices". These practices implied facing confrontation, difficult topics, and critical self-reflexivity. In summary "forefronting the complexities of doing engaged qualitative research" (2010, p.175).

To tackle the issue of differential power between the ethnographers and their host communities, the account of reflective practices has become more transparent. Besides, in the Americas, there is a long tradition of activism, which originated from the work of Frank Boas. Boas questioned evolutionism in social sciences; he argued that cultures cannot be objectively ranked as higher or lower, or better or more evolved. He argued instead that all humans make sense of the world through the lens of their own culture. Boas is credited with pioneering 'savage ethnography' which he justified for two reasons. One was that after decades of ethnocide, the indigenous peoples of North America were reduced and disappearing. The technological developments, languages and knowledge of these people could still be recorded and documented before surviving individuals died. The other was that Boas as a young Jewish German, witnessed the rise of anti-Semitism and then, when settled in the US, he also witnessed genocide against indigenous people. These experiences no doubt had an impact in his persona and an influence in his work. These may explain his commitment to scientific work as a way to counter social evolutionism and the racist and discriminatory politics it endorsed.

During the 1980s Roy Rapapport was preoccupied with the problem of ecological resilience or with the lack of it. He developed a framework for analysing adaptation maladaptation and called engaged anthropologists to work with research participants in figuring out solutions to the problems of maladaptation (Low and Merry 2010). Engaged anthropology had its critics, particularly as during the cold war, the Central Intelligence Agency (CIA) and the US army in some cases hired anthropologist to advance geopolitical projects. On other occasions, they targeted critical anthropologist who were working in areas of interest such as Centro America. Low and Merry (2010) illustrated the problem with the example of Nash (2007). Nash described how she, as a novice anthropologist, documenting the struggle of labour union in Cantel, Guatemala, had witnessed how the CIA orchestrated the coup of President Arbenz in 1954. Nash reminded of the warnings of Gluckman (2002 [1958]) about the risks of ignoring or denying the political context of fieldwork.

A way to confront and perhaps subvert the problem of power inequality is engaged anthropology, more so in the form of activism. Another proposed solution put forward by Bourdiau ([1977] 1984) is the radicalisation of participation. Under this perspective ethnography encompasses not only giving back results to host communities but also verifying 
local grammars. This solution proposed by Bourdiau, et al, (1994) implies that ethnographies must be devolved to local people who then validate the ethnographic data and outcomes, modifying, commenting, criticising and even rejecting the outcomes.

If engaged anthropology and radicalisation of participation sound revolutionary, even more provoking was the proposal of Colombian sociologist Fals-Borda (1984) of transforming sociological paradigm by conducting Participatory Action Research (PAR). In PAR, participation is throughout, from the moment a problem is formulated, continuing with the design of the methodology, to the form of presentation. In PAR there is no dominant epistemic; research is a collaborative process and outputs are co-authored.

\section{Conclusion}

The review of the genealogy of ethnography aimed to help develop an understating of what it is and how it came to be the dominant methodology for qualitative data analysis. It also helps to explain the difficulty of proposing a single definition of ethnography. Ethnography is a product, a craft and a method. This makes it very difficult the teaching of ethnography. Learning the craft implies practicing, it involves opening oneself to the vivid experience, and it requires discipline in managing the field diary, being aware of the epidemiology of others and of our own. It also involves reflective practice. All of these, makes it very difficult to provide a guide (or a formula) for becoming a successful ethnographer. Additionally, as an author, the ethnographer must constantly read and write until finding his/her own voice and style.

By reviewing this genealogy of ethnography, the reader must have realised the reasons for the wide appeal of this methodology. In our current age of Anthropocene, with the use of resilience as conceptual and mobilisation framework, there is growing interests in learning ethnography. Conducting research in transdisciplinary teams requires reflective practice, not only for analysis of qualitative data gathered and generated on the field, but also of the research process itself. Ethnography obligates deconstructing our own learning process, forces us to question how each participant of the investigation came to know or realised they learnt something new.

Ethnography also implies being aware and given account of power structures; it involves hypothesising and proving how power struggle affects knowledge co-production. The advancement in theory and policy for improving sustainability of livelihoods and for the promotion of territorial innovation systems requires reflexivity. Without reflective practices, the systematisation of information for advancing theory and policy development would be very limited.

\section{References:}

Boas, F. (1940) "The relation of Darwin to anthropology", notes for a lecture; Boas papers (B/B61.5) American Philosophical Society, Philadelphia. Published on line with Herbert Lewis 2001b, Race, Language, and Culture ISBN 0-226-06241-4

Bordieu, P. (1977) Outline of theory of practice. Cambridge Studies on Social and Cultural Anthropology. Cambridge: CUP (1984) A social critique on the judgment of taste. Cambridge, Massachusetts: Harvard University Press. 
Bordieu, P. Passeron J-C. and M. de Saint-Martin (1994) Academic Discourse:

Linguistic Misunderstanding and Professorial Power, Stanford: Stanford University Press

Clifford, J. and Marcus, G. (eds.) (1986) Writing culture: The poetics and politics of ethnography. Berkeley: University of California Press.

Convention on Biological Diversity - CBD (2010) Global Biodiversity Outlook 3. https://www.cbd.int/doc/publications/gbo/gbo3-final-en.pdf Accessed 27-07-2017.

Comte A. (1907) A General view of Positivism. London: George Routledge \& Sons.

Coquerwood, D. (1991) Rethinking ethnography: Towards a critical cultural policy. Communication Monographs. Vol. 58, No. 2

http://www.csun.edu/ vcspc00g/301/RethinkingEthnog.pdf

Coser L.A. (1977) Masters of Sociological Thought: Ideas in Historical and Social Context, 2nd edi., Fort Worth: Harcourt Brace Jovanovich, Inc. pp. 136-139.

Durkheim (1897, 1951) On Suicide. A Study in Sociology (Paris) New York: The Free Press. ISBN: 0-684-83632-7

Fals-Borda O. (1984) Development: Seeds of Change. 2:18-20.

Forero, O.A. (2015) Indigenous Perspectives of Sustainability and a Human Rights Approach to Sustainable Development. In Routledge International Handbook of Sustainable Development. Michael Redclift and Delyse Springett (eds.) Routledge: London and New York

Geertz, C. (1967) Under the Mosquito Net, A review of "A Diary in the Strict Sense of the Term" by Bronislaw Malinowski. The New York Review of Books Vol. 9, No. 4 September 14.

Geertz, C. (1983) Local Knowledge: Further essays in interpretative anthropology. NewYork: Basic Books

Geertz, C. (1988) Works and lives: The anthropologist as author. Standford: Standford University Press.

Gluckman, Max. 2002 (1958). "The bridge”: analysis of a social situation in Zululand. In The anthropology of politics: a reader in ethnography, theory, and critique. J. Vincent, ed. P. 476. Malden, MA: Blackwell.

Harris, M. (1976) History and Significance of the Emic/Etic Distinction. Annual Review of Anthropology. Vol. 5 (1976), pp. 329-350. Annual Reviews Stable URL: http://www.jstor.org/stable/2949316 
Headland T.N. (1990) A dialogue between Kenneth Pike and Marvin Harris on emics and etics, in Emics and Etcis: The outsider insider debate. Headland, T.N., Pike, K and M Harris, (eds.) Sage Publications.

Kruger S. (2008) Ethnography in the performing arts. The Higher Education Academy, Liverpool: JMU

Low S.M. and Merry S.E. (2010) Engaged Anthropology: Diversity and Dilemmas, Current Anthropology, Vol. 51, No. S2, (October 2010), pp. S203-S226. The University of Chicago Press on behalf of Wenner-Gren Foundation for Anthropological Research.

Malinowski, B. (1920) Kula: The Circulating Exchange of Valuables in the Archipelagoes of Eastern New Guinea. Man. Vol.20. pp 97-105.

Malinowski, B. (1922) The Argonauts of the North Pacific Ethnology and the Study of Society. London, G. Routledge \& Sons; New York, E.P. Dutton \& C

Malinowski, B. (1923). The Problem of Meaning in Primitive Languages. In The Meaning of Meaning: A Study of the Influence of Language upon Thought and of the Science of Symbolism C. K. Ogden, \& I. A. Richards (Eds.), The Meaning of Meaning. pp. 296-336. London: K. Paul, Trend, Trubner.

Malinowski, B. (1935) Coral Gardens and Their Magic, properly Coral Gardens and Their Magic: A Study of the Methods of Tilling the Soil and of Agricultural Rites in the Trobriand Islands. The language of Magic and Gardening. London: G. Allen and Unwin; New York: American Book Company.

Malinowski, B. (1935b) Coral Gardens and Their Magic II: The language of Magic and Gardening. London: G. Allen and Unwin; New York: American Book Company.

Malinowski, B. (1967) A Diary in the Strict Sense of the Term. London: Routledge and Kegan Paul Ltd.

Nanarpuzha, R. and Sharma D. (2013) Ethnography in marketing: Acceptance and relevance.http://vslir.iimahd.ernet.in:8080/xmlui/bitstream/handle/11718/11490/CB-PP214-Ethnography_in_Consumer_Research-135 Nanarpuzha_b.pdf?sequence $=1 \&$ isAllowed $=\mathrm{y}$ Accessed 05-07-2017.

Nash, June C. (2007) Practicing ethnography in a globalizing world: an anthropological odyssey. Lanham, MD: AltaMira.

Owen, B. (2011) Introduction to Cultural Anthropology: Class 7 Anthropological methods: Ethnography. 
http://bruceowen.com/introcultural/a203-11s-1-07 AnthMethodsEthnography.pdf Pike, K. (1954) Language in Relation to a Unified Theory of the Structure of Human Behaviour Summer Institute of Linguistics Glendale, CA.

Pike, K. (1959) Language as particle, wave and field. Texas Quarterly 2 (2): 37-54.

Pillow, W. (2003) Confession, catharsis, or cure? Rethinking the uses of reflexivity as methodological power in qualitative research. International Journal of Qualitative Studies in Education Vol. 16 , No. 2

Pineda Camacho, R. (1987) El método etnográfico un enfoque cualitativo de investigación social”. Texto y Contexto No1 Bogotá: Universidad de los Andes.

Rappaport, R. (1993) Distinguished lecture in general anthropology: the anthropology of trouble. American Anthropologist 95:295-303.

Scherer, G. (2012) IPCC predictions: Then versus now. The Daily Climate. Online periodical.http://www.dailyclimate.org/tdc-newsroom/2012/12/ipcc-prediction-fact-che ck Accessed 27-07-2017.

Simiand, F. (1912) La méthode positive en science économique, Paris, Félix Alcan, coll. Bibliothèque de philosophie contemporaine.

Tachi, J. Slater, D. and Hearn, G. (2003) Ethnographic Action Research: A user's handbook development to innovate and research ICT applications for poverty eradication. UNESCO: New Delhi.

United Nations (1987) Report on the World Commission Environment and Development: Our Common Future. Transmitted to the General Assembly as an annex to document A/42/427. http://www.un-documents.net/our-common-future.pdf Accessed 27-07-2017.

UNCCD (2017) Desertification: The invisible Frontline.

http://www.unced.int/Lists/SiteDocumentLibrary/Publications/Desertification_The\%20i nvisible_frontline.pdf Accessed 27-07-2017.

Van Maanen, J (1988) Tales from the field: On writing ethnography. Chicago: University of Chicago Press.

Venkatesh, A. Crockett, D. Cross, S. and Chen S. (2017), Ethnography for Marketing and Consumer Research, Foundations and Trends ${ }^{\circledR}$ in Marketing: Vol. 10: No. 2, pp 61-151. http://dx.doi.org/10.1561/1700000043 